\title{
Enlarged parietal foramina caused by mutations in the homeobox genes ALX4 and MSX2: from genotype to phenotype
}

\author{
Lampros A Mavrogiannis ${ }^{1,5}$, Indira B Taylor ${ }^{1}$, Sally J Davies ${ }^{2}$, Feliciano J Ramos ${ }^{3}$, \\ José L Olivares ${ }^{4}$ and Andrew OM Wilkie*,1
}

\begin{abstract}
${ }^{1}$ Weatherall Institute of Molecular Medicine, University of Oxford, John Radcliffe Hospital, Oxford, UK; ${ }^{2}$ Institute of Medical Genetics, University Hospital of Wales, Cardiff, UK; ${ }^{3}$ Sección Genética, Departamento Pediatría, Facultad de Medicina, Hospital Clínico Universitario, Universidad de Zaragoza, Zaragoza, Spain; ${ }^{4}$ Departamento Pediatría, Facultad de Medicina, Hospital Clínico Universitario, Universidad de Zaragoza, Zaragoza, Spain
\end{abstract}

Heterozygous mutations of the homeobox genes ALX4 and MSX2 cause skull defects termed enlarged parietal foramina (PFM) and cranium bifidum (CB); a single MSX2 mutation has been documented in a unique craniosynostosis (CRS) family. However, the relative mutational contribution of these genes to PFM/CB and CRS is not known and information on genotype-phenotype correlations is incomplete. We analysed $A L X 4$ and MSX2 in 11 new unrelated cases or families with PFM/CB, 181 cases of CRS, and a single family segregating a submicroscopic deletion of $11 \mathrm{p} 11.2$, including $A L X 4$. We explored the correlations between skull defect size and age, gene, and mutation type, and reviewed additional phenotypic manifestations. Four PFM cases had mutations in either ALX4 or MSX2; including previous families, we have identified six $A L X 4$ and six MSX2 mutations, accounting for $11 / 13$ familial, but only $1 / 6$ sporadic cases. The deletion family confirms the delineation of a mental retardation locus to within $1.1 \mathrm{Mb}$ region of $11 \mathrm{p} 11.2$. Overall, no significant size difference was found between ALX4- and MSX2-related skull defects, but the ALX4 mutation p.R218Q tends to result in persistent CB and is associated with anatomical abnormalities of the posterior fossa. We conclude that PFM caused by mutations in ALX4 and MSX2 have a similar prevalence and are usually clinically indistinguishable. Mutation screening has a high pickup rate in PFM, especially in familial cases, but is not indicated in CRS.

European Journal of Human Genetics (2006) 14, 151-158. doi:10.1038/sj.ejhg.5201526; published online 30 November 2005

Keywords: enlarged parietal foramina; craniosynostosis; proximal $11 \mathrm{p}$ deletion syndrome; mental retardation

Introduction

ALX4 and MSX2 encode homeodomain transcription factors that have evolved as pleiotropic developmental regulators in vertebrates. ${ }^{1,2}$ Their roles in skeletal pattern-

\footnotetext{
${ }^{*}$ Correspondence: Professor AOM Wilkie, Weatherall Institute of Molecular Medicine, University of Oxford, John Radcliffe Hospital, Oxford OX3 9DS, UK. Tel: + 441865 222619; Fax: + 441865 222500;

E-mail: awilkie@hammer.imm.ox.ac.uk

${ }^{5}$ Present address: Yorkshire Regional Genetics Laboratory, St James's University Hospital, Leeds, UK.

Received 5 April 2005; revised 22 September 2005; accepted 23 September 2005; published online 30 November 2005
}

ing, differentiation, and growth are revealed in $A l \times 4^{-/-}$and $M s \times 2^{-/-}$mice, which display craniofacial (including skull defects), axial and appendicular abnormalities in their complex phenotypes. ${ }^{3-5}$

In humans, heterozygous loss-of-function mutations of either MSX2 or ALX4 can result in skull vault defects, characteristically in the form of enlarged parietal foramina (PFM). In MSX2, seven different intragenic mutations and one whole-gene deletion have been described. ${ }^{6-9}$ In $A L X 4$, six distinct intragenic mutations have been reported; ${ }^{10-12}$ large deletions encompassing $A L X 4$ define the proximal $11 \mathrm{p}$ deletion syndrome (P11pDS; also known as Potocki- 
Shaffer syndrome). ${ }^{13}$ The mandatory features of this contiguous gene syndrome are PFM and multiple exostoses (caused by deletion of EXT2, which lies adjacent to $A L X 4$ ); variable features include severe developmental delay, facial dysmorphism and structural brain abnormalities. ${ }^{14}$ The dichotomous occurrence of either severe-profound mental retardation $(\mathrm{MR})$ or normal intelligence indicates the existence of a single and specific MR locus on proximal 11p. A comparative genotype-phenotype analysis in P11pDS, relying on all published data at the time, proposed that the MR locus lies within either of two, approximately $1 \mathrm{Mb}$-long, intervals: D11S1355-D11S903 (distal region) or D11S1361-D11S1344 (proximal region). ${ }^{13,14}$ Recently, a new informative P11pDS case without MR was reported, and the deletion boundaries in a previously published P11pDS family were reassessed. ${ }^{15}$ Together, these lines of evidence support exclusion of the distal interval.

Typical PFM are bilateral oval or round openings in the parietal bones on either side of the posterior sagittal suture. ${ }^{16}$ They are anatomically distinct from the normal, minute foramina that transmit anastomotic vessels, ${ }^{17}$ and are caused by delayed ossification during rapid calvarial expansion. $^{4,5}$ Frequently, PFM can be traced back to a central defect in infancy, extending between the anterior and posterior fontanelles; when this persists it is termed cranium bifidum (CB). However, a bony bridge usually develops along the midline axis, creating two separate foramina, which tend to decrease in size with age through circumferential bone growth (Figure 1). Eventually complete closure may occur, leading to clinical nonpenetrance. Anatomically, these abnormalities contrast with craniosynostosis (CRS), the premature fusion of the cranial sutures; significantly, CRS (without PFM) was the consistent phenotype in a single family transmitting a heterozygous p.P148 H mutation of MSX2 that augments DNA binding. ${ }^{18,19}$
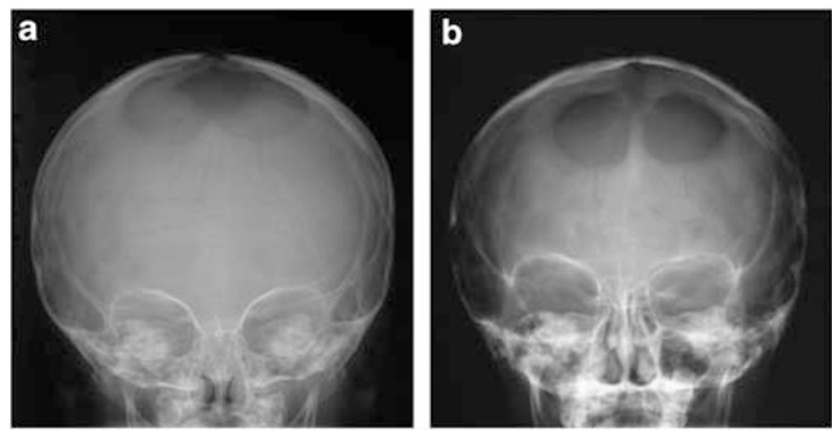

Figure 1 Skull radiographs of the female proband in family 11, heterozygous for the c.385 394del mutation of $A L X 4$. (a) At the age of $1 \frac{1}{3}$ years, $C B$ is evident. The defect occupies half the width of the skull and a small medial projection is visible. (b) At the age of 4 years, midline bridging has occurred marking off right and left, almost symmetric, PFM. In relative terms, the size of the defect has decreased.
Although the causal link between ALX4 and MSX2 mutations and PFM/CB is established, several questions remain. It is unknown whether PFM due to ALX4 and MSX2 mutations are clinically distinguishable: we describe four novel PFM-causing mutations (two per gene) and investigate the relationship of PFM size with age, mutant gene, and mutation type from collated radiological and molecular data. Until recently, it was unclear whether any additional abnormalities are part of the clinical spectrum. In one of our families transmitting an intragenic $A L X 4$ mutation there are vascular and cortical malformations of the brain similar to those previously observed in P11pDS, ${ }^{20}$ and we describe PFM and thumb/hallux broadening in a three-generation family segregating an $A L X 4$ mutation. The involvement of ALX4 and MSX2 mutations in CRS has not been systematically evaluated: here, we exclude intragenic mutations of either gene from a large disease cohort. Finally, we map the deletion in a P11pDS family without mental handicap, which provides independent confirmation that the MR locus resides in the proximal candidate region. ${ }^{15}$

\section{Subjects, materials, and methods Patients}

Clinical and laboratory investigations were conducted under research projects approved by the Central Oxford Research Ethics Committee.

Our PFM panel consisted of 20 unrelated families/cases with an established diagnosis of PFM or CB, representing 14 familial (kindreds 1-10, 12-14, 18) and six apparently sporadic cases with either isolated or syndromic defects. Mutations had been previously ascertained in families 1-9, while no molecular analysis has been reported in families 10-20. In these 11 new families, we tested samples from 19 affected individuals: the six probands in sporadic cases, five members of family 10 , the proband only in family 12 , three members of family 13, and two members each of families 14 and 18. Radiological assessment was by plain X-ray, computed tomography (CT), or magnetic resonance imaging (MRI). No individuals had signs suggestive of CRS, and at least one affected member per family had a normal Gbanded karyotype. Clinical and molecular details for four families with intragenic ALX4 mutations (families 1-4, family numbering preserved from the original report) have been published. ${ }^{11}$ Families with previously reported MSX2 mutations are numbered 5-7 (corresponding to families $1-3$, respectively, in the original report) ${ }^{6}$ and 8 (PFM and clavicular hypoplasia: PFMCH). ${ }^{8}$ Family 9, segregating a submicroscopic deletion of $11 \mathrm{p} 11.2$, was previously presented in abstract form: ${ }^{21}$ PFM, multiple exostoses, and normal intelligence were present in eight affected individuals in four generations. Four affected members were analysed: the female proband, two of her two sons, and her brother. To avoid ascertainment bias this family was excluded from comparisons of mutation prevalence. 
Families 10-13, in which we found novel mutations in either $A L X 4$ or MSX2, are previously unpublished. Familial PFM were ascertained in family 10 through three affected siblings. Additionally, they shared mild dysmorphic facial features (high forehead, narrow downturned palpebral fissures), high palate, tooth anomalies (dental malposition in one sibling, a single pair of upper incisors in the other two) and short, broad thumbs. PFM and broad thumbs were present in their father and paternal grandfather; the father also had a similar facial appearance. Microcephaly, present in two of the siblings, was also seen in their (PFMnegative) mother suggesting that this was a coincidental finding. Mental development was within normal limits in all affected individuals. No surgery had been performed.

The female proband in family 11 had a median skull defect in infancy that resolved into PFM during early childhood (Figure 1); the large openings were covered with titanium mesh at the age of 5 years. There was no evidence of skull defects in her sister or in either parent, but only the father was assessed radiologically. The family declined further testing.

Family 12 included an affected father and son. The former had a large parietal bone defect closed by bone grafting. His son had an enlarged posterior fontanelle and had a similar surgical procedure before the age of 1 year. The family history was otherwise reportedly negative and no other abnormalities were observed.

The proband in family 13 was referred as an infant with swelling of the occipito-parietal area and was subsequently found to have typical PFM. She had no neurological problems, her developmental milestones were normal, and the defects were managed conservatively. A male sibling was noted to have similar parietal bone defects shortly after birth. He was otherwise well except for a small muscular ventricular septal defect and patent ductus arteriosus, also managed conservatively. The mother was noted to have bilateral indentations of both parietal areas. As she had been adopted as a child, no previous family history was available.

Of the remaining families investigated, two have been detailed in case reports - families $14^{22}$ and $15 .^{23}$ In family 16 , the proband and her mother had an undiagnosed skeletal dysplasia, and PFM were present only in the proband. The female proband in family 17 had PFM, widespread cutis aplasia of the scalp, and hypoplasia of the terminal digits, suggestive of Adams-Oliver syndrome. In family 18, PFM and unilateral foot hexadactyly were seen in the proband at birth, but a skull radiograph at the age of 7 months was normal; the father had delayed skull ossification and agenesis of the lower central incisors. In family 19, PFM with pulsation transmitted through the openings were noticed in the proband at the age of 9 months. In family 20, PFM and hair agenesis in the overlying skin were present in the proband.

The CRS panel comprised 181 samples from patients with a diagnosis of either nonsyndromic or syndromic CRS in whom point mutations in the open reading frames of FGFR1, FGFR2, FGFR3, and TWIST1 had been excluded. ${ }^{24,25}$

\section{Molecular analysis of $A L X 4$ and MSX2}

The coding regions of $A L X 4$ and MSX2 were amplified using previously documented primer pairs., ${ }^{6,11}$ Samples from the new PFM families and the entire CRS panel were screened by denaturing high-performance liquid chromatography (DHPLC) on the WAVE DNA Fragment Analyser System (Transgenomic Ltd, Elancourt, France). Established conditions were employed for $M S X 2 ;^{8}$ for $A L X 4$, analyses were performed at $65^{\circ} \mathrm{C}$ and $67^{\circ} \mathrm{C}$ for exon $1,63^{\circ} \mathrm{C}$ and $65^{\circ} \mathrm{C}$ for exons 2 and 3 , and $65^{\circ} \mathrm{C}$ for exon 4 . Appropriate controls for the common polymorphisms were included.

Selected exons (or, for negative DHPLC results for PFM samples, the coding parts of $A L X 4$ and MSX2 in their entirety) were subjected to bidirectional DNA sequencing, using the BigDye terminator kit and an ABI PRISM 3100 sequencer (Applied Biosystems, Foster City, CA, USA). Traces were compared manually against genomic reference sequences (GenBank accession nos: AJ279074-AJ279077 for ALX4; L22498 and L22499 for MSX2) and numbering of variants in ALX4 and MSX2 is based on the cDNA sequences under GenBank accession nos AJ404888 and D89377, respectively, starting from the initiation codons.

All mutations and the two rare variants of $A L X 4$ in CRS were confirmed independently. In $A L X 4$, the c.605T $>\mathrm{G}$ and c.620C $>$ A substitutions create new restriction sites for NcoI and BfaI, respectively; the c.385_394del allele was detected by blot hybridisation with the oligonucleotide 5'-CGAGGCGCCCCCCGGACG-3'; and c.314_325del was cloned into pGEM-T Easy (Promega Corporation, Madison, WI, USA) and sequenced. In MSX2, the c.417_418del and c.456_465dup alleles were confirmed by blot hybridisation using the oligonucleotides 5'-GAGGAAACAAGACCAATC-3' and 5'-CAGCTCCTCCCAGCTCCT-3', respectively.

Dosage analysis was performed in all point mutationnegative PFM cases, using the multiplex ligation-dependent probe amplification assay (MLPA), as implemented in the P080-craniofacial MLPA kit (MRC-Holland, Amsterdam, The Netherlands).

\section{Statistical analysis}

Age and relative defect size (combined transverse width of the single or paired skull defects as a fraction of maximum skull width, measured on postero-anterior skull radiographs), were tabulated for all subjects with characterised ALX4 and MSX2 mutations for whom skull X-rays were available or have been reproduced in the literature. ${ }^{13,26-29}$ We included an additional published family, ${ }^{30}$ for which the original film was kindly provided by L Potocki and L Shaffer. The data set comprised 35 individuals with ALX4 mutations from 11 families and 17 individuals with MSX2 mutations from seven families. Multiple measurements at different ages were averaged so that each individual was represented 
by a single measurement. To account for the negative correlation between PFM width and age, we employed analysis of covariance (ANCOVA) with age as the covariate. Grouping was per locus and, within $A L X 4$, per mutation class; the homogeneity of variances was always tested.

\section{P11pDS characterisation}

Available members of family 9 were typed for 10 sequenceintegrated short tandem repeat (STR) loci on 11p11-p12. In telomere-to-centromere order, these were: D11S4173D11S1330-D11S1279-D11S905-D11S903-D11S2095-(ALX4)D11S2012-D11S4103-D11S554-D11S1361. Deletion characterisation was based on noninheritance of parental alleles and detection of heterozygosity. Fine delimitation of the centromeric breakpoint was by fluorescence in situ hybridisation (FISH) analysis, performed on metaphase spreads of lymphoblastoid cell lines according to standard protocols. The digoxygenin-labelled bacterial artificial chromosome (BAC) clones RPCI-11 58k22 (adjacent to D11S2012) and 193 f22 (containing D11S4103) were used as probes. Positional information for genes and STRs was retrieved through Ensembl v.22 (http://www.ensembl.org).

\section{Results}

Identification of additional $A L X 4$ and MSX2 mutations in PFM

Screening of 11 families with PFM identified four heterozygous mutations, two each in $A L X 4$ and MSX2. The ALX4 mutation c.620C > A (p.S207X) was identified in family 10: it was detected in all five affected individuals tested, who exhibited classical PFM, absent or malpositioned teeth, short and broad thumbs/halluces, and mild facial dysmorphism. A frameshifting deletion in ALX4, c.385_394del (predicting p.C129PfsX49), was found in the proband of family 11 . The apparently unaffected parents declined testing.

Both of the MSX2 mutations introduce frameshifts. A dinucleotide deletion, c.417_418del (predicting p.H139QfsX105), was detected in the father in family 12 and, presumably, had been transmitted to his affected son. A $10 \mathrm{bp}$ duplication, c.456_465dup (predicting p.A156PfsX92), was found in family 13 . The mutation was passed from the affected mother, who displayed isolated PFM, to her two children who both presented with a central parietal defect at birth.

\section{ALX4 and MSX2 mutations: clinical manifestations, phenotype-genotype relationships, and genetic mechanisms}

Table 1 summarises the clinical features associated with all published intragenic mutations in ALX4 and MSX2, inclusive of the above cases. Apart from the unique, gainof-function substitution p.P148H of MSX2 that enhances the DNA-binding affinity of the homeodomain, ${ }^{18,19}$ all other mutations either grossly disrupt the coding regions or affect conserved residues. Loss-of-function follows directly for the various nonsense and frameshift mutations,

Table 1 Intragenic $A L X 4$ and MSX2 mutations in humans

\begin{tabular}{|c|c|c|c|c|}
\hline Nucleotide change & Protein change $e^{\mathrm{a}}$ & Clinical features & References & Family no. \\
\hline \multicolumn{5}{|l|}{$A L X 4$} \\
\hline c.343_344insC & p.Q115PfsX43 & PFM $^{\mathrm{b}}$ & 12 & - \\
\hline c.385_394del & p.C129PfsX49 & PFM & This work & 11 \\
\hline c. $418 \overline{\mathrm{C}}>\mathrm{T}$ & p.Q140X & PFM/CB & 11,31 & 2 \\
\hline c.504del & p.D169TfsX12 & PFM & 10 & - \\
\hline c. $620 \mathrm{C}>\mathrm{A}$ & p.S207X & $\begin{array}{l}\text { PFM/CB, dental defects, facial dysmorphism, } \\
\text { broad and short thumbs/halluces }\end{array}$ & This work & 10 \\
\hline c. $653 G>A^{c}$ & p.R218Q & $\begin{array}{l}\text { PFM/CB, meningeal defects, neonatal } \\
\text { convulsions }\end{array}$ & $11,20,32$ & 3,4 \\
\hline c. $736 \mathrm{C}>\mathrm{T}$ & p.Q246X & $\mathrm{PFM} / \mathrm{CB}$ & 11 & 1 \\
\hline $\begin{array}{l}\text { C. } 815 G>C \\
M S X 2\end{array}$ & p.R272P & PFM & 10,26 & - \\
\hline c. $265 \_266$ delinsTA & p.A89X & PFM & 7,28 & - \\
\hline c. $345 \mathrm{del}$ & p.W115X & $\begin{array}{l}\text { PFM, scalp defects, meningeal, venous, and } \\
\text { cortical abnormalities }\end{array}$ & 7,29 & - \\
\hline c.417_418del & p.H139QfsX105 & PFM & This work & 12 \\
\hline c. $443 \bar{C}>A$ & p.P148H & Boston-type CRS & & \\
\hline c.456_465dup & p.A156PfsX92 & PFM, ventricular septal defect & This work & 13 \\
\hline c. $461 \overline{\mathrm{T}}>\mathrm{C}$ & p.L154P & PFM & & - \\
\hline c.468_484dup & p.R162PfsX24 & PFM, headaches, venous malformations & 9 & - \\
\hline c. $475-480 \mathrm{del}^{\mathrm{d}}$ & p.R159_K160del & PFM & 6 & 6 \\
\hline c.505_508dup & p.A170DfsX76 & PFMCH & 8 & 8 \\
\hline c. $515 \bar{G}>A^{c}$ & p.R172H & PFM, headaches & 6,7 & 7 \\
\hline
\end{tabular}

${ }^{a}$ Conceptual outcome; transcript and/or protein instability also likely for nonsense and frameshift-causing mutations.

${ }^{\mathrm{b}}$ Also MR, but most likely attributable to a concurrent duplication of $22 \mathrm{q} 12-\mathrm{q} 13$.

'Identified in two unrelated families.

${ }^{\mathrm{d}}$ Dental defects, observed in some affected individuals, segregated independently of the mutation (data not shown). 
some of which may target transcripts for nonsensemediated decay, although this is less likely for the changes occurring within the second (and terminal) exon of MSX2.

Focusing on the skull defects, a considerable number of cases have been documented both radiologically and molecularly, enabling analysis of phenotype-genotype correlation. An obvious question is whether there is a difference in severity between defects caused by ALX4 and MSX2 mutations. In Figure $2 \mathrm{a}$ the width of the defects, as a proportion of the skull width, is plotted in relation to age (data for ALX4 and MSX2 are shown separately). There is a significant negative correlation with age for mutations in either gene. To incorporate this age effect in the comparison of different mutation groups, we used analysis of covariance. Overall, no significant difference was found between ALX4 and MSX2 mutations (intragenic mutations and large deletions were combined in this analysis)
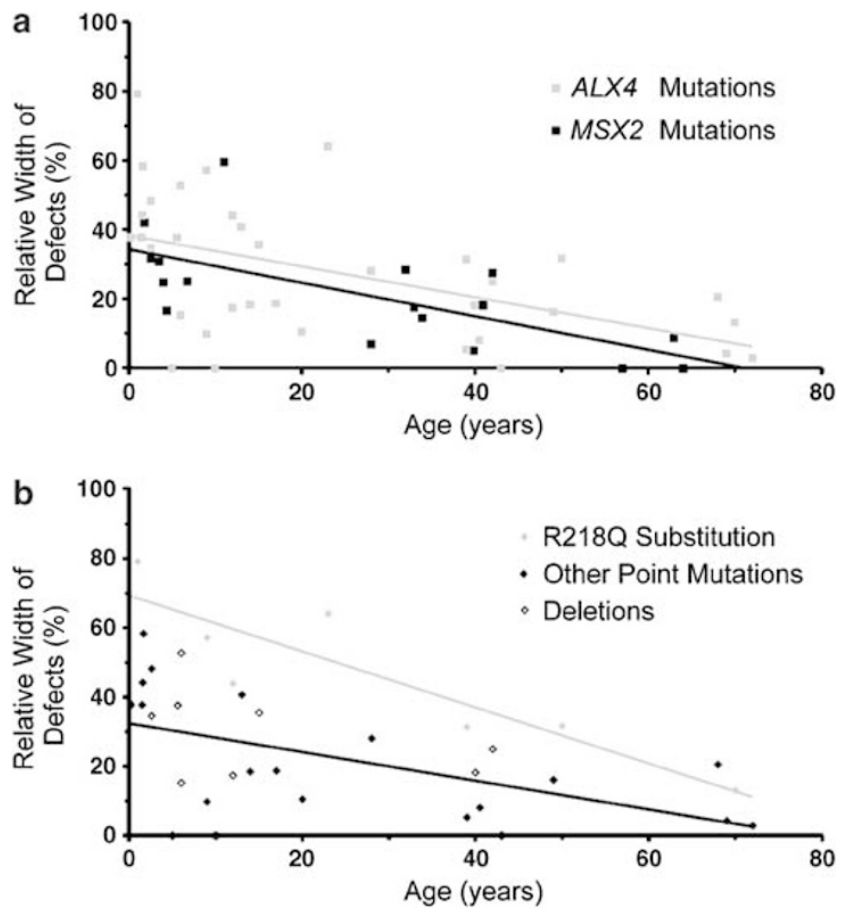

Figure 2 Comparison of the size of skull defects, expressed as fraction of maximum skull width, in different mutation classes. Annotated data sets are available as supplementary, internet-only material. (a) Intergenic $\operatorname{ALX} 4$ ( $n=35 ; 11$ families) vs MSX2 $(n=17 ; 7$ families) comparison. The relative defect width decreases significantly with age in both groups $(P<0.01)$. The slope coefficients for the linear regressions, reflecting the average ossification rate during postnatal life are -0.45 for $A L X 4$ and -0.48 for MSX2. ANCOVA, using age as the covariate, returns $P=0.30$ supporting the null hypothesis of no difference (homogeneity of variances test: $P=0.86$ ). (b) $A L X 4$ intragenic comparison between p.R218Q $(n=7 ; 2$ families) and all other point mutations and deletions ( $n=28 ; 9$ families). As previously, there is a negative correlation with age $(P<0.01)$, with slope coefficients -0.81 (p.R218Q) and -0.41 (all other mutations). ANCOVA rejects the null hypothesis of no difference: $P<0.001$ (homogeneity of variances test: $P=0.14$ ).
$(P=0.30)$. For $A L X 4$, sufficient cases were available to enable an analysis by mutation type. We found no difference between large deletions and intragenic mutations, considered collectively $(P=0.39)$. However, we noticed that subjects heterozygous for the p.R218Q substitution (present in seven individuals from two unrelated families) ${ }^{11,20,32}$ displayed disproportionately wide defects; when this mutation was compared against all other intragenic mutations and deletions, a significant difference was observed $(P<0.001)$ (Figure $2 \mathrm{~b})$. A dominant-negative effect appears likely (see Discussion), however, since the analysis is post hoc, replication of these observations would be valuable.

Apart from skull defects, certain other features appear to be causally associated with haploinsufficiency of $A L X 4$ or MSX2. In affected members of family 4, previously shown to carry the p.R218Q ALX4 mutation, ${ }^{11}$ neuroimaging demonstrated malformations of the posterior fossa, with polymicrogyria, wide spacing of the occipital lobes, persistence of the embryonic median prosencephalic vein with hypoplasia of the straight sinus, and high insertion of the tentorium cerebelli. ${ }^{20}$ The presentations are similar to that previously observed in association with ALX4 deletions, ${ }^{27,33}$ providing evidence that this malformation is attributable to deficiency of $A L X 4$ rather than to a contiguous gene. In family 10 a pattern of mild dysmorphism, dental abnormalities, and thumb broadening reminiscent of subtle preaxial polydactyly - co-segregated with the ALX4 mutation. These features have not been reported previously.

\section{Further delineation of P11pDS}

We characterised in detail the submicroscopic deletion in a three-generation P11pDS family, exhibiting PFM and exostoses of the long bones. ${ }^{21}$ None of eight affected individuals exhibited learning difficulties. STR typing defined the minimal region of hemizygosity as D11S1279-D11S2012 and mapped the outer limits of the deletion at D11S4173 distally and D11S554 proximally. Segregation of D11S4103, which lies near the proximal breakpoint between D11S2012 and D11S554, was uninformative. FISH mapping with two BACs (see Methods) confirmed the deletion at D11S2012, but indicated normal dosage at D11S4103 (data not shown). Thus, the deleted segment is quite large $(3.9-4.5 \mathrm{Mb})$, but very eccentrically placed with respect to $A L X 4$ (Figure 3 ). This event excludes a major MR locus for some distance telomeric to $A L X 4$ (see Discussion).

\section{Mutation analysis of $A L X 4$ and MSX2 in CRS}

To investigate the mutational contribution of MSX2 and ALX4 in CRS, our panel of undiagnosed patients was screened for sequence variants in the coding regions of the two genes. We found no uncommon variants in MSX2, but ascertained two heterozygous nonsynonymous changes in 
Table 2 Sequence polymorphisms within and around $A L X 4$ and MSX2 coding regions

\begin{tabular}{|c|c|c|c|}
\hline Nucleotide change & $\begin{array}{l}\text { Protein } \\
\text { change }\end{array}$ & Frequency estimate $^{a}$ & $\begin{array}{l}d b S N P \\
\text { reference }\end{array}$ \\
\hline \multicolumn{4}{|l|}{ ALX4 } \\
\hline c. $63 \mathrm{C}>\mathrm{T}$ & - & Rare & - \\
\hline c. $69 \mathrm{G}>\mathrm{C}$ & - & Very rare & - \\
\hline c. $104 G>C$ & p.R35T & $0.48(0.37-0.58)$ & rs3824915 \\
\hline c. $304 \mathrm{C}>\mathrm{T}$ & p.P102S & $0.43(0.32-0.53)$ & rs12421995 \\
\hline c. $594 \mathrm{C}>\mathrm{A}$ & - & $<0.03$ & \\
\hline c.729G $>A$ & - & $0.08(0.04-0.16)$ & rs11037928 \\
\hline c. $778-11 \mathrm{G}>\mathrm{A}$ & - & $0.06(0.02-0.13)$ & \\
\hline c. $879 \mathrm{C}>\mathrm{T}$ & - & $0.07(0.03-0.14)$ & rs12419361 \\
\hline c. $906+32 C>T$ & - & Very rare & \\
\hline c. $1074 \mathrm{C}>\mathrm{T}$ & - & $0.30(0.21-0.40)$ & rs3802805 \\
\hline c. $1282 \mathrm{G}>\mathrm{A}$ & - & Very rare & - \\
\hline c. $1392 \mathrm{G}>\mathrm{A}$ & - & Very rare & - \\
\hline c. $1464 C>T$ & - & $0.25(0.16-0.34)$ & rs4755798 \\
\hline \multicolumn{4}{|l|}{$M S \times 2$} \\
\hline c. $-17 C>G$ & - & $0.07(0.03-0.15)$ & rs4647952 \\
\hline c. $379+59 A>G$ & & Common & rs2048152 \\
\hline c. $386 \mathrm{C}>\mathrm{T}$ & p.T129M & $0.06(0.02-0.13)$ & rs4242182 \\
\hline
\end{tabular}

${ }^{\mathrm{a}} 95 \%$ confidence interval for the quantitative estimates.

Figure 3 Fine mapping of the MR locus in P11pDS. Definitively deleted segments are shown in dark grey with margins of uncertainty in light grey. Consideration of the new deletion event (case 6) along with previously published informative deletions (case $1 ;{ }^{13,15,30}$ case $2 i^{13}$ case $3 i^{15,34}$ case $4 i^{15,35}$ case $5^{15}$ ), variably associated with MR, definitively maps the relevant locus in the D11S1361-D11S1344 region. Markers run top-to-bottom in the telomere-to-centromere direction; EXT2 and ALX4 are located between D11S1393 and D11S2012.

ALX4 (c.314_325del encoding p.P105_Q108del; and c. $605 \mathrm{~T}>\mathrm{G}$ encoding p.L202W) of uncertain functional significance. Neither variant was found in a panel of 168 control chromosomes. The c.314_325del was also present in the patient's unaffected father, but parental samples were not available in the case of the p.L202W variant. Several other sequence variations in ALX4 and MSX2 were encountered, some of which have been documented previously; $;, 11,36$ these were considered to be nonpathogenic (Table 2).

\section{Discussion}

Overall, we identified $A L X 4$ or MSX2 mutations (six each) in $11 / 13$ familial but only $1 / 6$ sporadic PFM cases, suggesting that the two genes contribute approximately equally to the mutation spectrum. The difference in pickup rate between familial and sporadic cases is likely to reflect the relatively benign natural history of mutation-positive patients, enabling reproduction, and the higher frequency of complex/atypical manifestations in some of the sporadic cases that we analysed. Although we used DHPLC as our primary screening method, the large number of polymorphisms in ALX4 (Table 2) hampers this approach; instead, we recommend direct DNA sequencing. We analysed for small deletions using MLPA: although none was present in the mutation-negative cases (families 1420), dosage analysis should be part of any testing strategy. Further genetic heterogeneity is also likely to exist, as linkage analysis of a single extended kindred has suggested a third PFM locus on $4 \mathrm{q} .{ }^{37}$

The skull defects in mutation-positive cases show relatively high, but not full penetrance, and their severity and presentation may vary. Age is an important determinant and our analysis modelled its effect (Figure 2a). Nevertheless, residual variability and instances of nonpenetrance within families are compatible with the influence of genetic modifiers. In non-manifesting mutation carriers of either ALX4 or MSX2 mutations, we typed the reciprocal gene for coding variants (Table 2), but failed to detect any difference compared to clinically affected individuals (data not shown). We did not find any significant inter- or intragenic difference, save for the p.R218Q substitution in ALX4 (Figure 2b). Although haploinsufficiency is clearly the major genetic mechanism in PFM, the p.R218Q mutation may exert additional, dominant-negative effects. Previous in vitro binding assays on this variant suggested simple loss of function, ${ }^{38}$ but these studies were conducted under artificial conditions and relied on a generic DNA target. DNA-independent homodimerisation has been demonstrated in vitro for the two other members of the Alx group, the CART1 and ALX3 proteins; ${ }^{39,40}$ in the case of CART1 this extended to dominant-negative interference. ${ }^{39}$

In summary, despite the important biological differences between the ALX4 and MSX2 proteins, which belong to phylogenetically distant groups, ${ }^{41}$ have different biochemical properties, ${ }^{1,2}$ and appear to participate in pathways with limited or no overlap, ${ }^{5}$ the phenotypic outcome of 
heterozygous mutations is surprisingly similar, and is usually benign. In particular, we note that all affected individuals in the two families transmitting the ALX4 p.R218Q mutation have been managed conservatively without significant problems, despite the persistently large skull defects. Invasive closure of the defects has been practised and advocated, ${ }^{42}$ and certain patients in our series - with both ALX4 and MSX2 mutations - have had surgery. We advise careful weighting of the potential surgical complications (notably, graft failure and infection) against the benefits in the individual patient.

Although the most obvious impact of reduced dosage of ALX4 and MSX2 in humans is on skull vault growth, the posterior fossa abnormalities that have now been observed in association with both $A L X 4^{20,27,33}$ and $M S X 2^{29}$ mutations may also represent a shared defect that frequently goes unreported owing to the lack of brain imaging data. Alx 4 and Ms $x 2$ are both expressed in the ectomeninx, the outer mesenchymal condensation around the neural tube that forms the common primordium of the calvarial bones and the dura; ${ }^{43}$ independently, we detected $A l \times 4$ transcription in the falx cerebri. ${ }^{44}$ The similarity of the dural and calvarial abnormalities consequent upon reduced expression of both ALX4 or MSX2 suggests that a comparable defect in patterning of the ectomeninx underlies both disorders.

Some effects of ALX4 and MSX2 mutations may be genespecific. The dental and digital abnormalities observed in family 10 might represent ALX4-specific effects; Alx4 haploinsufficiency in the mouse is classically associated with polydactyly. $^{38}$ In the case of MSX2 mutations, proposed gene-specific effects have included abnormal clavicles, ${ }^{8}$ scalp, ${ }^{29}$ and dental defects. ${ }^{6}$ Modelling defects of the clavicles may be underreported, but MSX2 mutations were not found in a study of Adams-Oliver syndrome (featuring scalp and, usually, accompanying skull defects), ${ }^{36}$ and our further analysis of family 6 revealed discordance between the dental problems and the MSX2 mutation (data not shown).

A review of all overlapping deletions in P11pDS was thought to have defined two potential critical regions for putative MR loci: D11S1355-D11S903 or D11S1361D11S1344. ${ }^{14}$ However, a recent study showed that a deletion event, crucial to the above conclusion, had been erroneously characterised, ${ }^{13,30}$ and also presented a new case, without MR, locating the MR locus between D11S554-D11S1319 (Figure 3). ${ }^{15}$ The P11pDS family detailed here enables us to confirm this mapping. The segment D11S1361-D11S1344, being practically identical with D11S554-D11S1319, is not included in the family 9 deletion and seems highly likely to harbour an MR locus. It contains relatively few genes and can, potentially, be refined further using a previously published case. ${ }^{13}$ Candidate genes for haploinsufficiency effects in neurodevelopment include TSPAN18, producing a membrane-bound protein of the tetraspanin family; SYT13, specifying an atypical member of the synaptotagmin family; SLC35C1, encoding a GDP-fucose transporter; and PHF21A, producing a component of the BRAF-histone deacetylase complex.

Finally, we investigated the role of ALX4 and MSX2 mutations in CRS. This study was prompted by the detection of a unique MSX2 mutation, p.P148 H, in a family with $\mathrm{CRS}^{18}$ and the occasional occurrence of CRS in association with P11pDS. ${ }^{13,14}$ We encountered two ALX4 coding variants in single patients (out of 181 screened) that are not common polymorphisms. The p.P105_Q108del involves deletion of $4 / 15$ amino acids in a stretch comprised entirely of proline and glutamine. Although it has been proposed that length variations in such repeats might influence craniofacial morphology, ${ }^{45}$ the same deletion was present in the clinically unaffected father. The significance of the p.L202W substitution is uncertain as no other family members were available for analysis; however, in vertebrates this position is not fully conserved either in ALX4 orthologues or in its paralogues ALX3 and CART1, reducing the probability that it is pathogenic. Overall, our findings indicate that intragenic mutations of either gene are not common causes of CRS and are not worth screening for routinely. It remains a possibility that duplication of either gene might be associated with accelerated or enhanced calvarial ossification. This has been confirmed for MSX2, although the impact of such imbalance is variable; ${ }^{46}$ in a case with a likely duplication of $A L X 4$ there was no sign of CRS. ${ }^{47,48}$

\section{Acknowledgements}

We thank all the individuals and families who participated in this study; L Ades, D Bonthron, I Bueno, K Chrzanowska, CA Kim, $T$ Letteboer, $H$ Urbach, $S$ Wall, and I Zschocke for patient referral; $L$ Shaffer and L Potocki for sharing skull radiographs; N Elanko and $S$ Twigg for general technical and DHPLC support; L Kearney and $J$ Leach for assistance with FISH analysis; and K Clarke for DNA sequencing. This work was funded by the Alexander $S$ Onassis Foundation and the Medical Research Council (LA Mavrogiannis), the Ministerio de Sanidad of Spain, Programa de Redes Temáticas de Investigación Cooperativa, FIS-ISCIII (Grants: C03/07 to FJ Ramos and JL Olivares; G03/098 to FJ Ramos), and the Wellcome Trust (AOM Wilkie). LA Mavrogiannis wishes to dedicate this work to the memory of his father, Anastasios.

\section{References}

1 Meijlink F, Beverdam A, Brouwer A, Oosterveen TC, Ten Berge D: Vertebrate aristaless-related genes. Int J Dev Biol 1999; 43: 651 -663.

2 Alappat S, Zhang ZY, Chen YP: Msx homeobox gene family and craniofacial development. Cell Res 2003; 13: 429-442.

$3 \mathrm{Qu} \mathrm{S}$, Niswender KD, Ji Q et al: Polydactyly and ectopic ZPA formation in Alx-4 mutant mice. Development 1997; 124: 3999-4008.

4 Satokata I, Ma L, Ohshima $\mathrm{H}$ et al: Msx2 deficiency in mice causes pleiotropic defects in bone growth and ectodermal organ formation. Nat Genet 2000; 24: 391-395.

5 Antonopoulou I, Mavrogiannis LA, Wilkie AOM, Morriss-Kay GM: Alx4 and Msx2 play phenotypically similar and additive roles in skull vault differentiation. J Anat 2004; 204: 487-499. 
6 Wilkie AOM, Tang Z, Elanko $\mathrm{N}$ et al: Functional haploinsufficiency of the human homeobox gene MSX2 causes defects in skull ossification. Nat Genet 2000; 24: 387-390.

7 Wuyts W, Reardon W, Preis S et al: Identification of mutations in the MSX2 homeobox gene in families affected with foramina parietalia permagna. Hum Mol Genet 2000; 9: 1251-1255.

8 Garcia-Miñaur S, Mavrogiannis LA, Rannan-Eliya SV et al: Parietal foramina with cleidocranial dysplasia is caused by mutation in MSX2. Eur J Hum Genet 2003; 11: 892-895.

9 Bernier V, Ghassibé M, Boon LM, Vikkula M: A novel loss of function mutation in the MSX2 homeobox gene in a family with foramina parietalia permagna (PFM) [abstract]; The American Society of Human Genetics 54th Annual Meeting 2004; 436.

10 Wuyts W, Cleiren E, Homfray T, Rasore-Quartino A, Vanhoenacker F, Van Hul W: The ALX4 homeobox gene is mutated in patients with ossification defects of the skull (foramina parietalia permagna, OMIM 168500). J Med Genet 2000; 37: 916-920.

11 Mavrogiannis LA, Antonopoulou I, Baxová A et al: Haploinsufficiency of the human homeobox gene ALX4 causes skull ossification defects. Nat Genet 2001; 27: 17-18.

12 Gentile M, Wuyts W, Grittani S et al: Clinical, cytogenetic, and molecular characterization of a patient with a de novo interstitial 22q12 duplication. Am J Med Genet 2004; 127A: 186-190.

13 Bartsch O, Wuyts W, Van Hul Wet al: Delineation of a contiguous gene deletion syndrome with multiple exostoses, enlarged parietal foramina, craniofacial dysostosis, and mental retardation, caused by deletions on the short arm of chromosome 11 . Am J Hum Genet 1996; 58: 734-742.

14 Wuyts W, Waeber G, Meinecke P et al: Proximal 11p deletion syndrome (P11pDS): additional evaluation of the clinical and molecular aspects. Eur J Hum Genet 2004; 12: 400-406.

15 Wakui K, Gregato G, Ballif BC et al: Construction of a natural panel of $11 \mathrm{p} 11.2$ deletions and further delineation of the critical region involved in Potocki-Shaffer syndrome. Eur J Hum Genet 2005; 13: 528-540.

16 O'Rahilly R, Twohig MJ: Foramina parietalia permagna. Am J Roentgenol 1952; 67: 551-561.

17 Tubbs RS, Smyth MD, Oakes WJ: Parietal foramina are not synonymous with giant parietal foramina. Pediatr Neurosurg 2003; 39: $216-217$.

18 Jabs EW, Müller U, Li X et al: A mutation in the homeodomain of the human MSX2 gene in a family affected with autosomal dominant craniosynostosis. Cell 1993; 75: 443-450.

19 Ma L, Golden S, Wu L, Maxson R: The molecular basis of Bostontype craniosynostosis: the Pro148His mutation in the N-terminal arm of the MSX2 homeodomain stabilizes DNA binding without altering nucleotide sequence preferences. Hum Mol Genet 1996; 5: $1915-1920$.

20 Valente M, Valente KD, Sugayama SSM, Kim CA: Malformation of cortical and vascular development in one family with parietal foramina determined by an $A L X 4$ homeobox gene mutation. Am I Neuroradiol 2004; 25: 1836-1839.

21 Davies SJ, Norton N, Daniels JK, Owen MJ: Parietal foramina and multiple exostoses - familial inheritance of a molecular deletion [abstract]. Am J Hum Genet 1997; 61S: A95.

22 Solymosi L, Leuwer S, Wappenschmidt J: Foramina parietalia permagna. Radiologe 1987; 27: 269-272.

23 Chrzanowska K, Kozlowski K, Kowalska A: Syndromic foramina parietalia permagna. Am J Med Genet 1998; 78: 401-405.

24 Kan S, Elanko N, Johnson D et al: Genomic screening of fibroblast growth-factor receptor 2 reveals a wide spectrum of mutations in patients with syndromic craniosynostosis. Am J Hum Genet 2002; 70: $472-486$.

25 Elanko N, Sibbring JS, Metcalfe KA et al: A survey of TWIST for mutations in craniosynostosis reveals a variable polyglycine tract in asymptomatic individuals. Hum Mutat 2001; 18: 535-541.

26 Rasore-Quartino A, Vignola G, Camera G: Hereditary enlarged parietal foramina (foramina parietalia permagna). Prenatal diagnosis, evolution and family study. Pathologica 1985; 77: $449-455$
27 Yamamoto T, Akaboshi S, Ninomiya $\mathrm{H}$, Nanba E: DEFECT 11 syndrome associated with agenesis of the corpus callosum. J Med Genet 2001; 38: e5.

28 Schmidt-Wittkamp E, Christians H: Die lückenbildungen der scheitelbeine. Fortsch Gebiete Rontgenstr Nuklearmed 1970; 113: $29-38$.

29 Preis S, Engelbrecht V, Lenard H-G: Aplasia cutis congenita and enlarged parietal foramina (Catlin marks) in a family. Acta Paediatr 1995; 84: 701-702.

30 Shaffer LG, Hecht JT, Ledbetter DH, Greenberg F: Familial interstitial deletion $11(\mathrm{p} 11.12 \mathrm{p} 12)$ associated with parietal foramina, brachymicrocephaly, and mental retardation. Am J Med Genet 1993; 45: 581-583.

31 Kutilek S, Baxova A, Bayer M, Leiska A, Kozlowski K: Foramina parietalia permagna: report of nine cases in one family. J Paediatr Child Health 1997; 33: 168-170.

32 Salamanca A, Gonzalez-Gomez F, Padilla MC, Motos MA, Zorrilla F, Sabatel RM: Prenatal sonographic appearance of foramina parietalia permagna. Prenat Diagn 1994; 14: 766-769.

33 Wuyts W, Di Gennaro G, Bianco F et al: Molecular and clinical examination of an Italian DEFECT 11 family. Eur I Hum Genet 1999; 7: 579-584.

34 Potocki L, Shaffer LG: Interstitial deletion of 11(p11.2p12): a newly described contiguous gene deletion syndrome involving the gene for hereditary multiple exostoses (EXT2). Am J Med Genet 1996; 62: 319-325

35 Hall CR, Wu Y, Shaffer LG, Hecht JT: Familial case of PotockiShaffer syndrome associated with microdeletion of EXT2 and ALX4. Clin Genet 2001; 60: 356-359.

36 Verdyck P, Holder-Espinasse M, Van Hul W, Wuyts W: Clinical and molecular analysis of nine families with Adams-Oliver syndrome. Eur J Hum Genet 2003; 11: 457-463.

37 Chen G, Zhang D, Feng G, Liu W, He L: A novel locus for parietal foramina maps to chromosome 4q21-q23. J Hum Genet 2003; 48: $420-424$.

$38 \mathrm{Qu} \mathrm{S}$, Tucker SC, Ehrlich JS et al: Mutations in the mouse Aristaless-like4 cause Strong's luxoid polydactyly. Development 1998; 125: 2711-2721.

39 Furukawa $\mathrm{K}$, Iioka T, Morishita $\mathrm{M}$ et al: Functional domains of paired-like homeoprotein Cart1 and the relationship between dimerization and transcription activity. Genes Cells 2002; 7 $1135-1147$.

40 Pérez-Villamil B, Mirasierra M, Vallejo M: The homeoprotein Alx3 contains discrete functional domains and exhibits cell-specific and selective monomeric binding and transactivation. $J$ Biol Chem 2004; 279: 38062-38071.

41 Banerjee-Basu S, Baxevanis AD: Molecular evolution of the homeodomain family of transcription factors. Nucleic Acids Res 2001; 29: 3258-3269.

42 Kortesis B, Richards T, David L, Glazier S, Argenta L: Surgical management of foramina parietalia permagna. J Craniofac Surg 2003; 14: 538-544.

43 Rice R, Rice DPC, Olsen BR, Thesleff I: Progression of calvarial bone development requires Foxc1 regulation of Msx2 and Alx4. Dev Biol 2003; 262: $75-87$.

44 Mavrogiannis LA: The Roles of the Homeobox Genes ALX4 and MSX2 in Skull Development. DPhil thesis, University of Oxford, Oxford, 2003.

45 Fondon 3rd JW, Garner HR: Molecular origins of rapid and continuous morphological evolution. Proc Natl Acad Sci USA 2004; 101: 18058-18063.

46 Shiihara T, Kato M, Kimura T, Hayasaka K, Yamamori S, Ogata T: Craniosynostosis with extra copy of MSX2 in a patient with partial 5q-trisomy. Am J Med Genet 2004; 128A: 214-216.

47 Strobel RJ, Riccardi VM, Ledbetter DH, Hittner HM: Duplication $11 \mathrm{p} 11.3 \rightarrow 14.1$ to meiotic crossing-over. Am J Med Genet 1980; 7: $15-20$.

48 Hittner HM, Riccardi VM, Francke U: Aniridia caused by a heritable chromosome 11 deletion. Opthalmology 1979; 86: $1173-1183$ 